\title{
Modality of Particle Swarm Optimization to Improve Decision Making Process of Analytical Hierarchy Processing

\author{
${ }^{\pi}$ Prof. Suraj Bandichode, ${ }^{2}$ Prof. Bhumesh Masram, ${ }^{3}$ Prof. Sofia Pillai, ${ }^{4}$ Prof. Umesh Sakhare, ${ }^{5}$ Mr. Mayur \\ Wankhade \\ ${ }^{1,3,4} \mathrm{G}$ H Raisoni College of Engineering Nagpur \\ ${ }^{2}$ PICT Pune \\ ${ }^{5}$ IIT(ISM) Dhanbad \\ *Email: surajbanchad@gmail.com
}

\section{Received: 09 ${ }^{\text {th }}$ July 2018, Accepted: $14^{\text {th }}$ August 2018, Published: $31^{\text {st }}$ August 2018}

\begin{abstract}
AHP has been widely used in various real world applications. Numerous decision making process involves the use of pair-wise comparison matrix of AHP, and consistency ration is the most key issue related with AHP. In this research work, Particle Swarm Optimization algorithm is employed to reduce the consistency ratio of decision making process Analytical Hierarchy Process (AHP). The aim of proposed method is to reduce the CR. Consistency evaluation of AHP have been studied in literature since from 70's. The reported methods are quite complicated and difficult. Many methods could not maintain the original judgment provided by domain expert. We have presented a very simple and yet effective method to minimize of consistency ratio (almost zero) which will also preserves the domain expert's opinion. The robustness of proposed method is presented by applying it to real world case study. The experimentation shows that the proposed method is efficient and accurate to satisfy the consistency requirements of AHP.
\end{abstract}

Keywords: Particle Swarm Optimization, Consistency Ratio, Analytical Hierarchy Processing

\section{Introduction}

Various MCDM - Multi Criteria Decision Making techniques have been suggested and implemented in literature over pass three decades and for the adoption of weights most of these techniques used pair-wise comparison matrix which is reported (Saaty 2003). MCDM is a finite alternative selection problem based on given attributes. The significance of attributes in the decision making process was first incorporated by Saaty in Analytical Hierarchy Processing (AHP) to resolve the factors like quantitative and qualitative for decision makers. Analytical hierarchy processing has been applied widely on various cases studies and numerous applications. Pair wise comparison matrix in AHP is generally expressed on 1 to 9 scale by the decision makers, this decision making process is based on makers expertise and experience. Inconsistency in judgment and hence in pair-wise comparison matrix of AHP is most important issue to address. Consistency is also difficult to achieve when large numbers of attributes were considered. Even consistency can be raised due to limitations of experience and expertise. Revising the pair-wise comparison matrix and also to preserve the expertise judgment is challenging task and many existing approaches are very complicated and difficult to achieve it.

Consistency Ratio (CR) is computed as CI/RI where CR is Consistency Index and RI is Random Index. Saaty Suggested that, CR $<0.1$ is acceptable for the decision making process but practically it is very complicated process to achieve the $\mathrm{CR}$ while preserving judgment.

There are two mechanisms by which inconsistent pair wise matrices can be made consistent:

(1) The domain expert or decision maker can modify or reassess the matrix, however this approach is very time consuming.

(2) To get the optimal matrix values by either statistical approach or by optimization. This approach has taken attention of many researchers to modify the inconsistent pair-wise comparison matrix.

Researchers are using intelligent methods or techniques to modify the pair-wise matrix and to reduce the consistency ratio.

Lin et al., 2008 has used genetic algorithm to obtain the consistent matrices.

To solve the problem of inconsistent comparison, PSO and Taguchi method was applied (Yang et. al., 2012). Taguchi is applied to reduce the number of experiments required for PSO. Ant colony optimization (ACO) approach has implemented to solve inconsistency problem. ACO is used to enhance the minimal deviation matrix and to enhance the minimal consistent ratio (Girsang et al., 2014). Teaching Learning Based Optimization is used to tune the elements of pair-wise comparison matrix and two real world case studies from literature.

In this research work, a simple and efficient mechanism is proposed to tune the parameters of pair-wise matrix of AHP.

\section{Proposed Approach}

In this research work Particle Swarm Optimization is modelled is used to tune the elements of pair-wise comparison matrix. The Aim is to reduce the CR 
while preserving the domain expert's opinion in decision making process.

Step 1: Problem definition formulation, selection of alternatives based on attributes:

The decision table, given in Table I, shows alternatives, $\mathrm{Ai}$ (for $\mathrm{i}=1,2, \ldots, \mathrm{n}$ ), attributes, $\mathrm{Yj}$ (for $\mathrm{j}=1,2, \ldots, \mathrm{m}$ ), weights of attributes, wj (for $\mathrm{j}$ $=1,2, \ldots, \mathrm{m})$ and the measures of performance of alternatives, Xij (for $\mathrm{i}=1,2, \ldots, \mathrm{n} ; \mathrm{j}=1,2, \ldots, \mathrm{m}$ ). The problem is to choose the given alternative based on provided attributes.

\begin{tabular}{|c|c|c|c|c|c|}
\hline Alternatives & & & & & \\
\hline & Y1 & Y2 & - & - & Ym \\
\hline & (w1) & (w2) & & & (wm) \\
\hline A1 & $\mathrm{X} 11$ & $\mathrm{X} 12$ & - & - & X14 \\
\hline A2 & X21 & $\mathrm{X} 22$ & - & - & $\mathrm{X} 24$ \\
\hline A3 & X31 & X32 & - & - & X34 \\
\hline - & - & - & - & - & - \\
\hline- & - & - & - & - & - \\
\hline An & Xn1 & $\mathrm{Xn} 2$ & - & - & $\mathrm{Xnm}$ \\
\hline
\end{tabular}

TABLE I Decision Table in MADM Methods

Step 2. Preparation of normalized decision matrix:

There are two types of attributes, beneficiary and non-beneficiary. Beneficiary attributes means higher value is expected (example, Efficiency, Throughput etc) and non-beneficiary attribute means lower values is desired (example, cost, error etc). The normalization is carried out for an attributes by keeping desired value as 1 and rest values are made less than 1.

Step 3. Pair-wise matrix preparation of AHP:

Saaty suggested 1 to 9 scale of relative importance, wherein attributes can be compared among themselves on scale of $1,3,5,7$, and 9 are corresponds to judgments 'equal important', 'moderately important', 'strongly important', 'very strongly important' and 'absolutely important' respectively. $2,4,6$, and 8 are utilized when there is compromise between the above mentioned values Step 4: Variable identification for PSO:

The elements of matrix are chosen in a way that the minimum numbers of variables are selected for PSO and also the expert judgement is preserved.

Step 5: Deciding bounds of variables for PSO:

With assumption that, expert also can make minor wrong judgement which may result in max $10 \%$ of error in decision making process. To get the lower bound, it is current decision value -1 and to get upper bound / limit its current decision value +1 .

Step 6: Apply PSO to minimize consistency ratio

Let TM x M be the comparison matrix prepared in step 3 and $[\mathrm{UB}]$ and $[\mathrm{LB}]$ be the array of upper and lower bound respectively for the identified variables and $[\mathrm{X}]$ is array of variables.

PSO algorithm is applied to minimize the consistency ratio by tuning the identified variables within specified bound. Goal is to obtain the optimal comparison matrix OTM x $\mathrm{M}$ from TM x $\mathrm{M}$ by using PSO. Algorithm is as follows:

\footnotetext{
1. Initialize group of random particles

2. For each particle Calculate fitness value If the fitness value is better than the best fitness value (pBest) in history set current value as the new $p B e s t$

3. Update the velocity of particles Update the position of particles

4. Repeat the procedure from 2 to 3 until the termination criterion is met $(\mathrm{CR}<0.1)$.
}

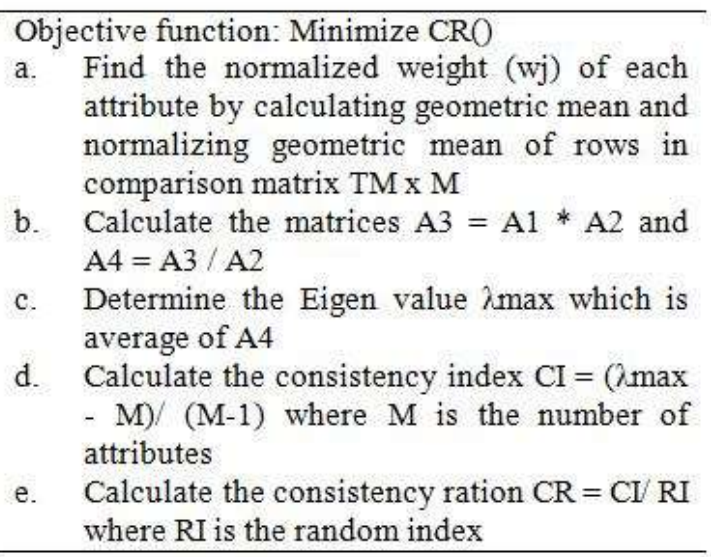

Step 7: Compute the consistency ration of optimal comparison matrix. Let OTM x M be the optimal matrix obtained by PSO.

Step 8: Compute the score of every alternative, which is summation of multiplication of weights and normalized data.

$P i=\Sigma w\left(C_{i j}\right)$ normalmj $=1$

where (Cij)normal represents the normalized value of $\mathrm{Cij}$, wj is the weight obtained correspond to the A2 matrix from step 7 and $\mathrm{Pi}$ is the overall or composite score of the alternative Ai.

\section{Result and Discussion}

Case study: Flexible Manufacturing Systems Evaluation: Flexible Manufacturing System (FMS) is capable of processing a wide variety of several parts parallel at several work places and it is composed of several processing work stations, usually connected by automated storage and material handling systems. Several attributes has influence in FMS and these attributes are: floor space required, cost involved, throughput time, labor requirement, setup cost, product-mix flexibility, routing, risk, utilization rate, payback period, volume flexibility, etc. To address issue of justification and computation of FMS, several mathematical and modeling methods has been proposed. A decision model using DEA for the evaluation of FMS is presented (Sarkis 1999). A distance-based fuzzy MCDM approach for the evaluation of FMS is presented and this method is 
similar to TOPSIS method (Karsak 2002). An AHP is used to implement FMS in tractor manufacturing plant (Bayazit 2005). A fuzzy multiple objective programming approach is proposed for the selection of a FMS (Karsak et. al., 2002). Authors had considered seven attributes and eight alternative FMS. 5 attributes are quantitative and 2 attributes are qualitative. Table II presents the data.

\begin{tabular}{llllllll}
\hline FM & RL & RW & RS & & & \\
S & C & P & C & IMR & IQ & CMC & FSU \\
1 & 30 & 23 & 5 & Good & Good & 1500 & 5000 \\
2 & 18 & 13 & 15 & Good & Good & 1300 & 6000 \\
3 & 15 & 12 & 10 & Fair & Fair & 950 & 7000 \\
4 & 25 & 20 & 13 & Good & Good & 1200 & 4000 \\
5 & 14 & 18 & 14 & Worst & Good & 950 & 3500 \\
6 & 17 & 15 & 9 & Good & Fair & 1250 & 5250 \\
7 & 23 & 18 & 20 & Fair & Good & 1100 & 3000 \\
8 & 16 & 8 & 14 & Worst & Fair & 1500 & 3000 \\
\multicolumn{7}{c}{ Table II: Objective Data of Flexible } \\
\hline \multicolumn{7}{c}{ Manufacturing System } \\
\hline
\end{tabular}

RLC: Labor cost reduction (\%)

RWP: WIP reduction (\%)

RSC: set up cost reduction (\%)

IMR: market response improvement

IQ: quality improvement

CMC: Capital and maintenance cost $(\$ 1,000)$

FSU: Floor space used (sq. ft.)

Step 1: The objective is to is evaluate the given alternatives (selection of best of alternative) based on provided attributes. In this work, RWP, RLC, RSC, IQ, IMR, CMC and FSU are considered as attributes. IMR and IQ are the qualitative attributes, whose equivalent values are obtained by using fuzzy scale. Final the problem having alternatives and their measures is provided in Table III.

\begin{tabular}{|c|c|c|c|c|c|c|c|}
\hline FMS & RLC & RWP & RSC & IMR & IQ & CMC & FSU \\
\hline I & 30 & 23 & 5 & 0.745 & 0.745 & 1500 & 5000 \\
\hline II & 18 & 13 & 15 & 0.745 & 0.745 & 1300 & 6000 \\
\hline III & 15 & 12 & 10 & 0.500 & 0.500 & 950 & 7000 \\
\hline IV & 25 & 20 & 13 & 0.745 & 0.745 & 1200 & 4000 \\
\hline V & 14 & 18 & 14 & 0.255 & 0.745 & 950 & 3500 \\
\hline VI & 17 & 15 & 9 & 0.745 & 0.500 & 1250 & 5250 \\
\hline VII & 23 & 18 & 20 & 0.500 & 0.745 & 1100 & 3000 \\
\hline VIII & 16 & 8 & 14 & 0.255 & 0.500 & 1500 & 3000 \\
\hline
\end{tabular}

TABLE III: Flexible Manufacturing System Data

Step 2: Data normalization:

Values belongs to different domain of units are normalized in the range of 0 to 1 . Here RLC, RWP, RSC, IMR and IQ are beneficial attributes, whereas CMC and FSU are the non-beneficiary attributes. The values for these attributes are normalized and are presented in Table IV.

\begin{tabular}{|l|l|l|l|l|l|l|l|}
\hline FMS & RLC & RWP & RSC & IMR & IQ & CMC & FSU \\
\hline I & 1 & 1 & 0.25 & 1 & 1 & 0.6333 & 0.6 \\
\hline II & 0.6 & 0.5652 & 0.75 & 1 & 1 & 0.7308 & 0.5 \\
\hline III & 0.5 & 0.5217 & 0.5 & 0.6711 & 0.6711 & 1 & 0 \\
\hline IV & 0.8333 & 0.8696 & 0.65 & 1 & 1 & 0.7917 & 0.75 \\
\hline & & & & & & & 0.857 \\
V & 0.4667 & 0.7826 & 0.7 & 0.3423 & 1 & 1 & 1 \\
\hline & & & & & & & 0.571 \\
VI & 0.5667 & 0.6527 & 0.45 & 1 & 0.6711 & 0.76 & 4 \\
\hline VII & 0.7667 & 0.7826 & 1 & 0.6711 & 1 & 0.8636 & 1 \\
\hline VIII & 0.5333 & 0.3478 & 0.7 & 0.3423 & 0.6711 & 0.6333 & 1 \\
\hline
\end{tabular}

TABLE IV. Data of Attributes (Normalized) of

FMS Problem

Step 3: Next step is to decide the relative importance by saaty's scale.

Here every attribute is compared with others and judgements are to be decided by domain expert.

\begin{tabular}{l|lllllll|} 
& RL & RW & RS & IM & I & CM & FS \\
& C & P & C & R & Q & C & U \\
RL & 1 & 1 & 3 & 1 & $1 /$ & $1 / 3$ & 3 \\
$\mathrm{C}$ & & & & & 3 & & \\
$\mathrm{RW}$ & 1 & 1 & 3 & 1 & $1 /$ & $1 / 3$ & 3 \\
$\mathrm{P}$ & & & & & 3 & & \\
$\mathrm{RS}$ & $1 / 3$ & $1 / 3$ & 1 & $1 / 3$ & $1 /$ & $1 / 5$ & 1 \\
$\mathrm{C}$ & & & & & 5 & & \\
$\mathrm{IM}$ & 1 & 1 & 3 & 1 & $1 /$ & $1 / 3$ & 3 \\
$\mathrm{R}$ & & & & & 3 & & \\
$\mathrm{IQ}$ & 3 & 3 & 5 & 3 & 1 & 1 & 5 \\
$\mathrm{CM}$ & 3 & 3 & 5 & 3 & 1 & 1 & 5 \\
$\mathrm{C}$ & & & & & & & \\
$\mathrm{FS}$ & $1 / 3$ & $1 / 3$ & 1 & $1 / 3$ & $1 /$ & $1 / 5$ & 1 \\
$\mathrm{U}$ & & & & & 5 & &
\end{tabular}

Step 4: Decision of variable for PSO:

$\left[\mathrm{X}_{\mathrm{i}}\right]=[1,3$,

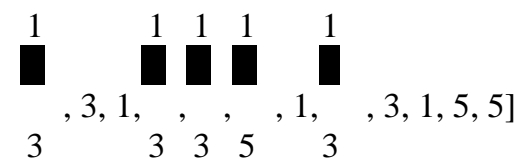

Step 5: Deciding upper and lower limits for variables:

\begin{tabular}{|l|l|l|l|l|l|l|l|}
\hline$[\mathrm{Xi}]$ & 1 & 3 & $1 / 3$ & 3 & 1 & $1 / 3$ & $1 / 3$ \\
\hline $\begin{array}{l}\text { Lower } \\
\text { bound }\end{array}$ & 1 & 2 & $1 / 2$ & 2 & 1 & $1 / 2$ & $1 / 2$ \\
\hline $\begin{array}{l}\text { Upper } \\
\text { bound }\end{array}$ & 2 & 4 & $1 / 4$ & 4 & 2 & $1 / 4$ & $1 / 4$ \\
\hline$[\mathrm{Xi}]$ & 5 & $1 / 5$ & 1 & $1 / 3$ & 3 & 1 & 5 \\
\hline $\begin{array}{l}\text { Lower } \\
\text { bound }\end{array}$ & 4 & $1 / 4$ & 1 & $1 / 2$ & 2 & 1 & 4 \\
\hline $\begin{array}{l}\text { Upper } \\
\text { bound }\end{array}$ & 6 & $1 / 6$ & 2 & $1 / 4$ & 4 & 2 & 6 \\
\hline
\end{tabular}

TABLE V. Upper Limit and Lower Limit of Variables 
Step 6: Apply PSO to get optimal matrix

\begin{tabular}{|c|c|c|c|c|c|c|c|}
\hline & RLC & $\begin{array}{l}\mathrm{RW} \\
\mathrm{P} \\
\end{array}$ & $\begin{array}{l}\mathrm{RS} \\
\mathrm{C} \\
\end{array}$ & $\begin{array}{l}\mathrm{IM} \\
\mathrm{R}\end{array}$ & IQ & $\begin{array}{l}\mathrm{CM} \\
\mathrm{C} \\
\end{array}$ & $\begin{array}{l}\mathrm{FS} \\
\mathrm{U} \\
\end{array}$ \\
\hline \multirow[t]{2}{*}{ RLC } & 1 & 1.1 & 2 & 1.1 & 0.4 & 0.4 & 2 \\
\hline & 0 & 97 & $\begin{array}{r}19 \\
4\end{array}$ & 97 & 683 & 683 & 194 \\
\hline \multirow[t]{2}{*}{ RWP } & 0.9 & 1 & 2.8 & 1.5 & 0.4 & 0.4 & 2.8 \\
\hline & 11 & 0 & $\begin{array}{r}77 \\
0\end{array}$ & $\begin{array}{r}62 \\
7\end{array}$ & 941 & 941 & 770 \\
\hline \multirow[t]{2}{*}{ RSC } & 0.4 & 0.3 & 1 & 0.4 & 0.1 & 0.1 & 1 \\
\hline & 952 & 476 & 0 & $\begin{array}{r}41 \\
3\end{array}$ & 989 & 989 & 686 \\
\hline \multirow[t]{2}{*}{ IMR } & 0.9 & 0.6 & 2.2 & 1 & 0.4 & 0.4 & 2.6 \\
\hline & 11 & 399 & $\begin{array}{r}66 \\
0\end{array}$ & 0 & 156 & 156 & 763 \\
\hline \multirow[t]{2}{*}{ IQ } & 2.1 & 2 & 5 & 2.4 & 1 & 1 & 4.2 \\
\hline & 354 & 239 & $\begin{array}{r}27 \\
7 \\
\end{array}$ & 62 & 0 & 863 & 764 \\
\hline \multirow[t]{2}{*}{$\mathrm{CMC}$} & 2.1 & 2 & 5 & 2.4 & 0.9 & 1 & 4.7 \\
\hline & 354 & 239 & $\begin{array}{r}27 \\
7\end{array}$ & 62 & 206 & 0 & 191 \\
\hline \multirow[t]{2}{*}{ FSU } & 0.4 & 0.3 & 0.9 & 0.3 & 0.2 & 0.2 & 1 \\
\hline & 952 & 476 & $\begin{array}{r}35 \\
8\end{array}$ & $\begin{array}{r}73 \\
7\end{array}$ & 338 & 119 & 0 \\
\hline
\end{tabular}

Step 7: Compute the consistency ratio using optimal matrix

Weights of attribute (normalized) are as follows, RLC $=0.1215, \mathrm{RWP}=0.1392, \mathrm{RSC}=0.0528, \mathrm{IMR}=$ $0.1115, \mathrm{IQ}=0.2627, \mathrm{CMC}=0.2602$ AND FSU $=$ 0.0522 . The value of $\lambda \max$ is 7.0381 and $C R=$

0.0047 , which is much less (almost zero) than the allowed CR value of 0.1 .

Consistency Ratio value of 0.0105 is obtained using proposed method, which is very less as compared to desired value of CR and as compared to original pairwise matrix. Thus, there is good consistency obtained by using PSO for the expert's pair-wise comparison matrix.

Step 8: Final step is to obtain the rank based on calculated scores (refer equation 8).

The comparison of ranks and scores obtained by proposed mechanism versus original pair-wise matrix is shown in Table VI. It is observed that the rankings for FMS 6, 7 and 8 are changes.

\begin{tabular}{lll|ll}
\hline FMS & \multicolumn{1}{l}{ original } & \multicolumn{1}{l}{ pair- } & Optimal & pair-wise \\
& wise comparison & \multicolumn{2}{l}{$\begin{array}{l}\text { comparison } \\
\text { obtained }\end{array}$} & using TLBO \\
& matrix & & \multicolumn{2}{l}{ Thix } \\
I & Score & Rank & Score & Rank \\
II & 0.8439 & 3 & 0.8441 & 3 \\
III & 0.7954 & 5 & 0.7815 & 5 \\
IV & 0.7107 & 6 & 0.6934 & 7 \\
V & 0.8801 & 1 & 0.8759 & 1 \\
VI & 0.8213 & 4 & 0.8083 & 4 \\
VII & 0.8730 & 2 & 0.8692 & 2 \\
VIII & 0.5871 & 8 & 0.5816 & 5
\end{tabular}

TABLE VI. Selection Rank and Score for FMS

\section{Conclusion}

In this research work, a simple and efficient mechanism is proposed based on particle swarm optimization to tune the parameters of pair-wise comparison matrix of AHP. In this research work, PSO has been applied to reduce the consistency ration of Analytical hierarchy processing and robustness of proposed method is presented with case study. The other intelligent algorithm also might be used to solve this problem.

\section{References}

1. Bayazit O. Use of AHP in decision-making for flexible manufacturing systems. Journal of Manufacturing Technology Management, vol. 16, no. 7, pp. 808-819, 2005.

2. Sarode M. Modality of Teaching Learning Based Optimization Algorithm to reduce the consistency ratio of the pair-wise comparison matrix in Analytical Hierarchy Processing. Evolving Systems, DOI 10.1007/s12530-0179185-9, 2017.

3. Girsang A, Tsai C, and Yang C. Ant algorithm for modifying an inconsistent pairwise weighting matrix in an analytic hierarchy process. Neural Comput \& Applic, vol. 26, no. 2, pp. 313-327, 2014.

4. Karsak E. Distance-based fuzzy MCDM approach for evaluating flexible manufacturing system alternatives. International Journal of Production Research, vol. 40, no. 13, pp. 31673181, 2002.

5. Karsak E and Kuzgunkaya O. A fuzzy multiple objective programming approach for the selection of a flexible manufacturing system. International Journal of Production Economics, vol. 79, no. 2, pp. 101-111, 2002.

6. Lin $\mathrm{C}$, Wang $\mathrm{W}$, and $\mathrm{Yu} \mathrm{W}$. Improving AHP for construction with an adaptive AHP approach (A3). Automation in Construction, vol. 17, no. 2, pp. 180-187, 2008.

7. Saaty T L. 2003. Decision-making with the AHP: Why is the principal eigenvector necessary. European Journal of Operational Research 145 (1), 85-91.

8. Sarkis $\mathrm{J}$ and Talluri S. A decision model for evaluation of flexible manufacturing systems in the presence of both cardinal and ordinal factors. International Journal of Production Research, vol. 37, no. 13, pp. 2927-2938, 1999.

9. Yang I, Wang W and Yang T. Automatic repair of inconsistent pairwise weighting matrices in analytic hierarchy process. Automation in Construction, vol. 22, pp. 290-297, 2012. 